\title{
Microwave Extraction of Eugenol from Cloves: A Greener Undergraduate Experiment for the Organic Chemistry Lab
}

\author{
Brittany J. Crouse ${ }^{1}$, Emily L. Vernon ${ }^{2}$, Brittany A. Hubbard ${ }^{1}$, Stella Kim ${ }^{3}$, \\ Melinda C. Box ${ }^{1}$, Maria T. Gallardo-Williams ${ }^{1, *}$ \\ ${ }^{1}$ Department of Chemistry, North Carolina State University, Raleigh, North Carolina 27695, United States \\ ${ }^{2}$ Department of Biochemistry, North Carolina State University, Raleigh, North Carolina 27695, United States \\ ${ }^{3}$ Green Hope High School, Cary, North Carolina 27519, United States \\ *Corresponding author: Maria_Gallardo@ncsu.edu
}

Received December 01, 2018; Revised January 08, 2019; Accepted January 22, 2019

\begin{abstract}
The extraction of eugenol from cloves is a frequent experiment in organic chemistry labs at the sophomore level. In this paper, the commonly used steam distillation procedure has been modified to use microwave extraction. This change resulted in a simplified procedure, a reduction in the amount of sample required, and an increase in the efficiency of the extraction of eugenol from dried cloves. These modifications led to reduction of waste and energy use. Variations of the solvent composition, solvent volume, and amount of cloves were tested. It was found that a $50 / 50 \mathrm{v} / \mathrm{v}$ mixture of ethanol and water with whole cloves produced satisfactory results at the undergraduate laboratory level for the selective extraction of eugenol with $1 \mathrm{~g}$ of whole cloves in less time than steam distillation.
\end{abstract}

Keywords: second-year undergraduate, organic chemistry, laboratory instruction, natural products, green chemistry

Cite This Article: Brittany J. Crouse, Emily L. Vernon, Brittany A. Hubbard, Stella Kim, Melinda C. Box, and Maria T. Gallardo-Williams, "Microwave Extraction of Eugenol from Cloves: A Greener Undergraduate Experiment for the Organic Chemistry Lab." World Journal of Chemical Education, vol. 7, no. 1 (2019): 21-25. doi: 10.12691/wjce-7-1-3.

\section{Introduction}

Of all the experiments routinely performed in organic chemistry labs, those involving the extraction of essential oils from vegetable matter have been part of the repertory of chemical educators for many years; the extraction of oil from cloves is a classic example. Not only does the extract of cloves have a pleasant smell, but also direct practical applications as a flavoring agent, antioxidant [1], antifungal agent [2], local anesthetic [3], and nutraceutical [4]. Procedures for the steam distillation of oil from cloves abound $[5,6]$ and several modifications such as extraction with liquid carbon dioxide [7], and extraction using pressurized hot water with a commercial espresso machine [8] have been recently described. Both studies attempt to circumvent the use of steam distillation, and aim to design a greener version of the experiment. Steam distillation is time consuming, requires large amounts of starting material, and the use of distillation equipment as well as hot plates or heating mantles.

A recent paper compares several methods for the extraction of eugenol from cloves, including steam distillation, soxhlet extraction, and microwave-assisted extraction [9]. Using the existing procedures, oil of cloves is isolated which must then be subjected to an acid-base extraction in order to separate its two components: eugenol and acetyleugenol (Figure 1). Alternatively, the mixture of eugenol and acetyleugenol can be analyzed using gas chromatography. In this paper a simplified procedure is described for the extraction of pure eugenol from cloves in good yields using a microwave. The choice of an appropriate solvent system allowed for the selective separation of eugenol, without traces of acetyleugenol. This represents an advantage over existing extraction methods, since it eliminated the need for separation of the two components of clove oil after the extraction. Compared to the original steam distillation, the modifications presented here make it possible to complete the experiment in less time, using reduced amounts of reagents, and generating less waste.

Recent articles describe the use of microwave ovens in the undergraduate laboratory $[10,11]$ and highlight the convenience and time savings associated with microwave methods. This microwave technique not only extracts the essential oils at a low enough temperature to prevent decomposition, but the microwave's lower energy demand makes it a greener alternative to existing methods. In the experiment presented here, switching from distillation to 
microwave extraction made it possible to simplify the procedure since it reduced the need for further purification. Batch processing of students' extraction mixtures was accomplished using a sample carrousel, and the design of that carrousel was adaptable to a varying number of samples. Due to the efficiency of this method, smaller sample sizes and solvent quantities can be used while still extracting enough eugenol for characterization by infrared spectroscopy (IR).

In addition to the experimental development, a student-generated video $[12,13]$ was produced describing the use of the microwave equipment to novices. The video is short and can be viewed as part of the pre-lab preparation or in the lab prior to use of the microwave [14]. It can be accessed using an embedded link in the experimental procedure, or on-demand by scanning a barcode placed on the instrument.<smiles>C=CCc1ccc(O)c(OC)c1</smiles><smiles>C=CCc1ccc(OC(C)=O)c(OC)c1</smiles>

Figure 1. Structures of eugenol and acetyleugenol, major components of clove oil

The main pedagogical goal for this experiment was to isolate a natural product using a microwave-based extraction technique. Students were expected to perform sequential solid-to-liquid and liquid-to-liquid extractions in order to obtain eugenol from cloves. This exercise would provide them with experience in the laboratory use of microwave heating technology.

\section{Procedure}

\subsection{Method Development}

The microwave extraction method development was done by undergraduate students as part of a summer research project. Initially optimal solvent composition was determined by varying the water-to-ethanol ratio, as well as testing pure dichloromethane. As summarized below in Table 1, the 50/50 ethanol/water mix worked best for this application. It not only produced better yields compared to the other solvent mixes, but it also produced a better yield than the steam distillation method, i.e. an average of $12.6 \pm 0.1 \%$ versus $10.1 \%$ for steam distillation. This solvent mix had the added benefit of extracting only the eugenol, thereby eliminating the need for a subsequent acid-base extraction to isolate it from the acetyleugenol, as would have been needed if the sample were obtained by steam distillation. The liquid-liquid extraction required for the isolation of eugenol can be completed using dichoromethane or n-pentane. Yields are better with dichloromethane, but since n-pentane is a safer solvent and the amounts isolated are enough for IR characterization, we suggest it as a viable alternative.

Table 1. Solvents and solvent mixtures tested for optimization

\begin{tabular}{cccc}
\hline $\begin{array}{c}\text { Solvent for } \\
\text { microwave } \\
\text { extraction }\end{array}$ & $\begin{array}{c}\text { Solvent for } \\
\text { eugenol } \\
\text { isolation }\end{array}$ & $\begin{array}{c}\text { Average } \% \\
\text { yield }\end{array}$ & $\begin{array}{c}\text { Acetyleugenol } \\
\text { detected via IR }\end{array}$ \\
\hline $\begin{array}{c}50 \% \text { aqueous } \\
\text { ethanol }\end{array}$ & dichloromethane & 12.7 & No \\
$\begin{array}{c}50 \% \text { aqueous } \\
\text { ethanol }\end{array}$ & n-pentane & 4.9 & No \\
$\begin{array}{c}\text { 95\% aqueous } \\
\text { ethanol } \\
\begin{array}{c}\text { Dichloromethane } \\
\text { Water (Steam } \\
\text { distillation) }\end{array}\end{array}$ & dichloromethane & 14.4 & Yes \\
\hline
\end{tabular}

The optimal clove-to-solvent ratio and total solvent quantity were also determined. The ratio was varied between $0.1 \mathrm{~g} / \mathrm{mL}$ and $0.2 \mathrm{~g} / \mathrm{mL}$ and the total solvent was varied between $5 \mathrm{~mL}$ and $10 \mathrm{~mL}$. It was found that the optimal ratio of cloves to solvent was $0.1 \mathrm{~g} / \mathrm{mL}$ and the optimal solvent quantity for student use was $10 \mathrm{~mL}$, as shown in Table 2.

Table 2. Varying Solvent-to-Sample Ratio and Total Volume of $50 \%$ Ethanol

\begin{tabular}{ccc}
\hline $\begin{array}{c}\text { Ratio } \\
\text { (g cloves: } \mathrm{mL} \text { solvent })\end{array}$ & Total volume $(\mathrm{mL})$ & Average \% yield \\
\hline $1: 10$ & 10 & 12.5 \\
$1: 10$ & 5 & 6.0 \\
$1: 5$ & 5 & 9.0 \\
\hline
\end{tabular}

\subsection{Experimental Procedure}

A detailed procedure is provided as Supporting Information. Briefly, Cloves (1 g) and a microwave-safe stir bar were covered with $10 \mathrm{~mL}$ of solvent $(50 \% \mathrm{v} / \mathrm{v} /$ ethanol/water $)$ in a microwave reaction vessel fitted with a Teflon threaded cap. The samples were evenly spaced around the microwave carrousel and loaded. A control vessel containing only 10 $\mathrm{mL}$ of the ethanol solution and a temperature probe was also loaded on the carrousel. After heating and cooling a liquid-liquid extraction followed. The product was a dark orange oil that had an intense smell. Samples were analyzed via TLC (solvent was 1:2 mixture of pentane and dichloromethane) and characterized by IR spectroscopy. The spectra obtained were compared to a reference spectrum to confirm the identity of the product as eugenol [15].

\subsection{Hazards}

The use of adequate personal protection equipment, including eye protection, by students and instructors was required at all times in the laboratory. Dichloromethane can irritate the lungs, skin, and eyes and can affect the central nervous system if breathed so it was used in a fume hood. Ethanol was handled with care due to flammability. Clove oil is an irritant and was handled with care. Used solvents and eugenol samples were disposed of in the organic liquid waste stream. Leftover cloves were safely disposed of in a trash receptacle. 


\section{Results and Discussion}

This experiment was designed to produce an alternative to steam distillation which is the traditional undergraduate laboratory method used for obtaining eugenol from cloves [6]. This extraction of natural products from plant sources is a widely used introductory organic chemistry experiment, and it could be beneficial to have a method that addresses green chemistry principles such as being more energy efficient and using less sample. Even compared to recent alternatives developed for extraction of eugenol from cloves, such as use of an espresso machine [8], microwave extraction is more energy efficient, requires less solvent, and provides comparable yields. In addition, this modified microwave procedure was short enough to allow time for characterization in the same lab period while improving the yield as compared to steam distillation.

The energy savings from microwave use rather than a heating mantle, as would be used in steam distillation is $96 \%$. This was determined by assuming one section of 10 groups (20 students) runs all samples in the reaction microwave at an average of 100 Watts for $15 \mathrm{~min}$ (based on the power output profile recorded by the microwave's software), and comparing that to a 200-Watt heating mantle run at approximately $70 \%$ power for $30 \mathrm{~min}$ by each group in a section to do distillation. Therefore, microwave use consumes $9 \mathrm{~kJ}$ per group and the heating mantle $252 \mathrm{~kJ}$ per group. By contrast, and espresso machine consumes approximately $20-30 \mathrm{~kJ}$ per shot and in the procedure reported by Just et al [8] this would be done twice. Thus microwave use would still provide at least a $20 \%$ energy savings compared to an espresso machine extraction.

Solvent use was also reduced in two ways, first by optimizing the initial amount required for solid-to-liquid extraction, and second by eliminating the need for subsequent liquid-to-liquid extraction. This experiment was tested as described here with two classes of Organic Chemistry I Lab - one class of 40 students in two sections and a second class of 36 students in two sections - taught by two different teaching assistants. All students finished in the allotted time ( $3 \mathrm{hrs}$ ), and all of them obtained enough product to complete the characterization step. Eliminating the steam distillation step and the time required to cool the distillate, as well as the lengthy liquid-liquid extraction to remove the acetyleugenol not only made this method greener, it made it faster, taking only 20-25 $\mathrm{min}$ in the microwave and $30 \mathrm{~min}$ average time to work up the mixture and get an IR spectrum of the sample. The time required to complete the extraction was been reduced in half (compared to steam distillation/liquid-liquid extraction), which left more time for students to spend on the elucidation of the IR spectrum.

Using the steam distillation method many students were unable to isolate and characterize the extracted eugenol in one lab period, which in turn required students to complete the product characterization outside of class time (students submitted product for IR spectroscopy, were sent the IR via e-mail and returned the lab report the following week). In contrast, with the method presented here, it was possible to complete the microwave extraction quickly, which allowed students to have ample time for product characterization. In a lab with inexperienced students, being able to take IR spectra and devote time to understanding the results was not trivial, and it resulted in increased student engagement in the characterization process, when compared to sections from previous semesters using steam distillation for the same purpose.

\section{Conclusions}

Student outcomes from this experiment were assessed by using the same instrument previously used to assess the outcomes of the steam distillation extraction. There was no significant change in student grades for this experiment due to the technique change between the courses that used this method compared to steam distillation. Sample TLC and IR results from students are provided in the Supporting Information. From a laboratory management standpoint the setup required was much simpler, glassware breakage was negligible, and less waste was generated. In this context the microwave extraction procedure was considered a viable and attractive choice for use in second-year organic chemistry labs.

\section{Acknowledgements}

The authors are thankful for the support of the Chemistry Department at North Carolina State University. The Office of Faculty Development provided funds in the form of a Community Engagement mini-grant. Helpful comments were received from the teaching assistants that tested this experiment: Veronica Hubble and Christopher Poteat.

\section{References}

[1] Shan, B.; Cai, Y. Z.; Sun, M.; Corke, H. Antioxidant capacity of 26 spice extracts and characterization of their phenolic constituents. J. Agric. Food Chem. 2005, 53, 7749-7759.

[2] Pinto, E. N.; Vale-Silva, L. S.; Cavaleiro, C.; Salgueiro, L. G.; Antifungal activity of the clove essential oil from Syzygium aromaticum on Candida, Aspergillus and dermatophyte species. $J$. Medi. Microbiol. 2009, 58, 1454-1462.

[3] Alqareer, A.; Alyahya, A.; Andersson, L. The effect of clove and benzocaine versus placebo as topical anesthetics. J. Dentistry 2006. 34, 747-750.

[4] Khalil, A.A.; ur Rahman, U.; Khan, M.R.; Sahar, A.; Mehmood, T.; Khan, M. Essential oil eugenol: sources, extraction techniques and nutraceutical perspectives. RSC Adv., 2017, 7, 32669-32681.

[5] Ntamila, M. S.; Hassanali, A. Isolation of oil of clove and separation of eugenol and acetyleugenol. J. Chem. Educ. 1976, 53, 263.

[6] Williamson, K. L. Macroscale and Microscale Organic Experiments, D.C. Heath and Company: Lexington, MA, 1989.

[7] Barcena, H.; Chen, P. An anesthetic drug demonstration and an introductory antioxidant activity experiment with "Eugene, the sleepy fish". J. Chem. Educ. 2016, 93, 202-205.

[8] Just, J.; Bunton, G. L.; Deans, B. J.; Murray, N. L.; Bissember, A. C.; Smith, J.A. Extraction of eugenol from cloves using an unmodified household espresso machine: An alternative to traditional steam distillation. J. Chem. Educ. 2016, 93, 213-216.

[9] Guntero, V.A.; Mancini, P.M.; Kneeteman, M.N. Introducing organic chemistry students to the extraction of natural products found in vegetal species. World J. Chem. Educ. 2017, 5, 142-147.

[10] Baar, M. R.; Falcone, D.; Gordon, C. Microwave-enhanced organic synthesis for the undergraduate laboratory: Diels-Alder cycloaddition, Wittig reaction, and Williamson ether synthesis. $J$. Chem. Educ. 2010, 87, 84-86.

[11] Baar, M. R.; Gammerdinger, W.; Leap, J.; Morales, E.; Shikora, J.; Weber, M. H. Pedagogical comparison of five reactions performed 
under microwave heating in multi mode versus mono-mode ovens: Diels-Alder cycloaddition, Wittig salt formation, E2 dehydrohalogenation to form an alkyne, Williamson ether synthesis, and Fischer esterification. J. Chem. Educ. 2014, 91, 1720-1724.

[12] Jordan, J. T.; Box, M. C.; Eguren, K. E.; Parker, T. A.; SaraldiGallardo, V. M.; Wolfe, M. I.; Gallardo-Williams, M. T. Effectiveness of student-generated video as a teaching tool for an instrumental technique in the organic chemistry laboratory. J. Chem. Educ. 2016, 93 (1), 141-145.
[13] Box, M.C.; Dunnagan, C.L.; Hirsh, L.A.S.; Cherry, C.R.; Christianson, K.A.; Gibson, R.J.; Wolfe, M.I.; Gallardo-Williams, M.T. Qualitative and quantitative evaluation of three types of student-generated videos as instructional support in organic chemistry laboratories. J. Chem. Educ. 2017, 94 (2), 164-170.

[14] "MARS 6 Microwave" https://www.youtube.com/watch?v=D1ENvc8pEjI

[15] Bio-Rad/Sadtler IR Data Collection. Bio-Rad Laboratories, Philadelphia, PA (US).

\title{
Supporting Information
}

Procedure and Outcomes

\section{Instructor Materials}

\author{
Supplies \\ - Whole cloves (1g per group of students) \\ - MARS 6 Synthesis microwave \\ - Microwave reaction vessel fitted with Teflon threaded caps \\ - MARS 6 temperature probe \\ - $50 \% \mathrm{v} / \mathrm{v}$ ethanol/water \\ - Pentane \\ - Anhydrous sodium sulfate \\ - TLC plates \\ - TLC chambers \\ - TLC spotters \\ - 1:2 mixture of pentane and dichloromethane
}

\section{Procedure}

\section{General Considerations}

Cloves were store-bought and used whole. All solvents used were commercially available without further purification. Students worked in pairs for one, 3-h laboratory period under the supervision of a graduate teaching assistant to complete the experiment.

\section{Microwave Extraction}

Cloves ( $1 \mathrm{~g})$ and a microwave-safe stir bar were covered with $10 \mathrm{~mL}$ of solvent $(50 \% \mathrm{v} / \mathrm{v} / \mathrm{ethanol} / \mathrm{water})$ in a microwave reaction vessel fitted with a Teflon threaded cap. The samples were evenly spaced around the microwave carrousel and loaded in a MARS 6 Synthesis microwave (CEM Corp, Matthews, NC). A control vessel containing only $10 \mathrm{~mL}$ of the ethanol solution and a temperature probe was also loaded on the carrousel. The samples were run simultaneously at $1000 \mathrm{~W}$ with a 10 -minute ramp and a 5-minute holding period at $95^{\circ} \mathrm{C}$. The vessels were left to cool for 15 minutes until the mixture was no longer boiling. The resulting liquid was separated from the cloves and placed into a large test tube. Since the microwave carrousel could hold 24 samples at once, all the samples for one lab section could be processed at the same time. A student-generated video describing the use of the microwave and highlighting relevant operational details and safety features [14] was made available to the students and teaching assistants. A detailed procedure for students, worksheet for data collection, and instructor's notes are provided as Supporting Information.

\section{Solvent Extraction}

Microscale extraction was performed in the test tube containing the solution. Pnetane was used as the extraction solvent. After adding $2 \mathrm{~mL}$ of dichloromethane, the test tube was shaken and the two layers were allowed to separate. The organic layer was removed into a clean test tube. The extraction was repeated 2 additional times. The solution was dried with anhydrous sodium sulfate. After $5 \mathrm{~min}$ the liquid was filtered and the solvent was evaporated from a 50 -mL beaker placed on a hot plate under a bench-top hood. Once the extraction in completed the sample can be evaporated using a rotary evaporator to recover the solvent.

\section{Analysis}

The product was a dark orange oil that had an intense smell. Samples were analyzed via TLC (solvent was 1:2 mixture of pentane and dichloromethane) and characterized by IR spectroscopy. The spectra obtained were compared to a reference spectrum to confirm the identity of the product as eugenol [15]. 
Hazards

The use of adequate personal protection equipment, including eye protection, by students and instructors was required at all times in the laboratory. Dichloromethane can irritate the lungs, skin, and eyes and can affect the central nervous system if breathed so it was used in a fume hood. Ethanol was handled with care due to flammability. Clove oil is an irritant and was handled with care. Used solvents and eugenol samples were disposed of in the organic liquid waste stream. Leftover cloves were safely disposed of in a trash receptacle.

Procedure Details

The samples were run at $1000 \mathrm{~W}$ with a 10 -minute ramp and a 5 - minute hold at $95^{\circ} \mathrm{C}$ (you can modify the default Diels-Alder pre-programmed sequence on the MARS 6 Synthesis microwave for this purpose).

Student materials

TLC plate

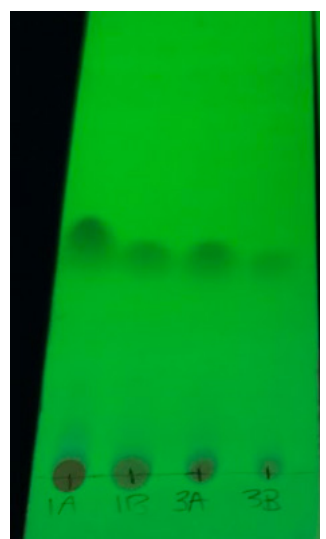

IR spectrum

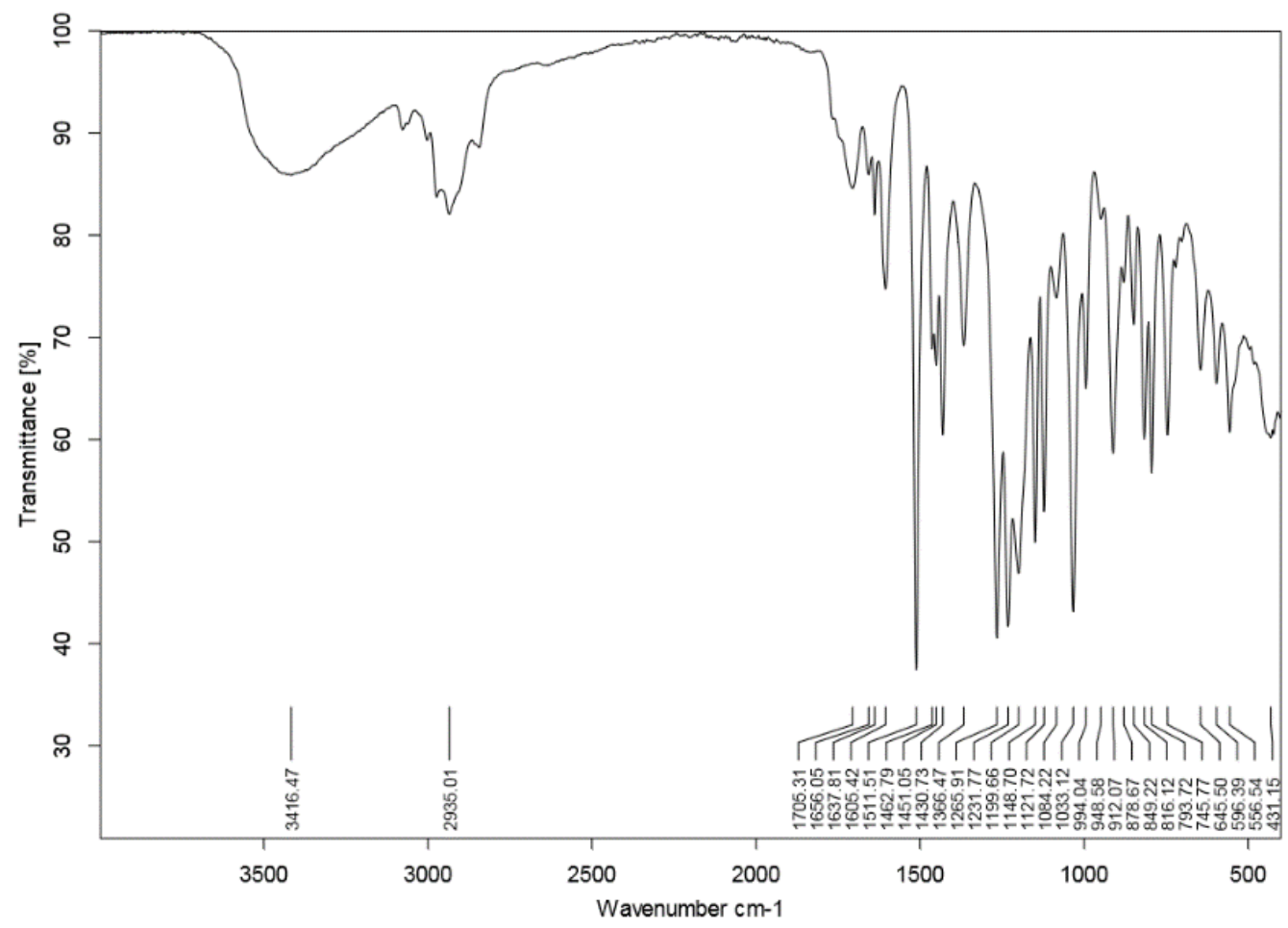

(C) The Author(s) 2019. This article is an open access article distributed under the terms and conditions of the Creative Commons Attribution (CC BY) license (http://creativecommons.org/licenses/by/4.0/). 